\title{
Seawalls do not sustain viable populations of limpets
}

\author{
J. Moreira*, M. G. Chapman, A. J. Underwood \\ Centre for Research on Ecological Impacts of Coastal Cities, Marine Ecology Laboratories A11, University of Sydney, \\ New South Wales 2006, Australia
}

\begin{abstract}
Increasing urban development in coastal areas is leading to reduction and fragmentation of natural habitats and a proliferation of artificial structures, such as seawalls. These new structures provide a novel habitat for several organisms, but recent studies have shown differences between the composition of populations in assemblages inhabiting them and those present on natural rocky shores. Preliminary observations also suggested that populations of limpets may differ in size and reproductive output between seawalls and natural rocky shores in Sydney Harbour (Australia). To test hypotheses about the influence of artificial habitat on populations of marine invertebrates, we examined the densities, size and reproductive output of the pulmonate limpet Siphonaria denticulata at midshore intertidal levels on several seawalls and natural rocky shores in Sydney Harbour. Populations on seawalls were mainly composed of juveniles and small adults; large adults were generally found only on rocky shores. There were also significantly fewer and smaller egg masses on seawalls. Experimental manipulations suggested that differences in reproductive output are related to the maximal size that adults attain in each habitat. Populations on seawalls make a smaller contribution to the total reproductive output in any given area, and, thus, it can be predicted that replacement of natural habitats with seawalls may have negative effects on the maintenance of local populations. Populations of organisms living in different habitats in similar densities may show important differences in biological performance. Thus, differences in reproductive output between habitats, even at the same densities, will potentially influence dynamics of populations of limpets.
\end{abstract}

KEY WORDS: Urbanisation · Habitat · Seawall · Rocky shore $\cdot$ Intertidal $\cdot$ Reproduction · Limpets Siphonaria denticulata

Resale or republication not permitted without written consent of the publisher

\section{INTRODUCTION}

Urban areas currently house nearly half of the world's human population (Lim \& Sodhi 2004), and it is expected that this proportion will grow to $60 \%$ by the year 2030 (Pickett et al. 2001). This trend means a continuous increase in the expansion of cities and towns and, therefore, a conversion of natural landscapes to human-modified urban landscapes (Collinge 1996). Urbanisation removes and fragments natural habitats and results in a number of new structures being added to the environment (McDonnell \& Pickett 1990, Glasby $\&$ Connell 1999). To date, most research on the effects of urbanisation in terrestrial habitats has been focused on habitat fragmentation and performance of species in remaining patches of natural habitat (Fahrig \& Merriam 1994, Dooley \& Bowers 1998, Krauss et al. 2003).
The consequences of development of new structures that replace and fragment natural habitat have not, however, been widely explored. For some habitats, it is not known whether fragmentation by building something is more or less of an influence on sustainability of species than would be the case for other types of fragmentation. On the other hand, where there have been studies of artificial structures, they tend to note whether abundances of animals are similar to those in natural habitats (Dickman \& Doncaster 1987, Madejczyk et al. 1998, Laakkonen et al. 2001). When separated from demographic functionality, density may, however, lead to wrong conclusions about the value of artificial structures as alternative habitats, because they may just act as ecological sinks in which organisms fail to breed successfully (Smallwood 2001). Consequently, survival of populations in these artificial 
habitats will depend on immigration from other sources (Watkinson \& Sutherland 1995). There is, therefore, an urgent need to assess the impact of artificial structures and their value as alternative habitats that can sustain viable populations.

Loss of habitat is especially widespread in coastal marine systems (Moberg \& Rönnbäck 2003) and is the most critical threat to marine biodiversity (Gray 1997). Declines and extinctions of species can, for example, be associated with the loss of habitat needed for the completion of critical parts of the life-cycle (McDowall 1992). Growing urbanisation in coastal areas can lead to the reduction and fragmentation of natural habitats and a subsequent increase in artificial structures, like jetties, pilings, pontoons and seawalls (Glasby \& Connell 1999, Wolff 1999, Davis et al. 2002, Chapman \& Bulleri 2003, Bulleri \& Chapman 2004). These new structures are made of a variety of materials and differ from natural habitats in terms of composition, orientation, features of the surface and provision of microhabitats (Chapman \& Bulleri 2003).

Although it has been suggested that seawalls provide a novel habitat and might act as surrogates for rocky shores (Thompson et al. 2002), recent studies have shown important differences between intertidal seawalls and natural rocky shores in terms of composition of biological assemblages and relative abundance of common species (Chapman 2003, Chapman \& Bulleri 2003, Bulleri \& Chapman 2004). In addition, little attention has been paid to the study of the ecological processes of intertidal assemblages on artificial structures (Bulleri et al. 2000, Bulleri 2005), and there have not been any studies on the viability of populations on seawalls.

Approximately $50 \%$ of the intertidal habitat in Sydney Harbour (New South Wales, Australia) consists of seawalls and similar artificial habitats (Chapman \& Bulleri 2003). Such extensive creation of artificial habitats allows tests of some potential consequences of fragmentation by unnatural surfaces. In particular, it provides a system for investigating whether maintenance of density of species in the artificial habitat is sufficient to sustain populations and ecological processes.

Grazing gastropods are among the most abundant mobile organisms on rocky shores in New South Wales (Underwood 1978, Creese 1981) and play a major role in structuring intertidal assemblages (Underwood \& Jernakoff 1981, Hawkins \& Hartnoll 1983, Petraitis 1987). Among them, the pulmonate limpet Siphonaria denticulata is one of the numerically dominant grazers on shores with moderate exposure to wave action (Creese \& Underwood 1982). This limpet lays benthic egg-ribbons, and their reproductive season extends from November to May (Creese 1980). The limpet also lives on seawalls (Chapman 2003), but preliminary observations suggested that, although there appeared to be large densities on seawalls, the sizes of limpets and lengths and numbers of egg-ribbons appeared to be smaller than on natural rocky shores. If seawalls are not providing suitable habitat to sustain breeding populations of these limpets, there are potentially serious consequences of replacing natural habitat with seawalls. We hypothesised that if seawalls were inadequate habitats for successful breeding by limpets, there would be less fecundity per capita on seawalls than in natural habitats.

We therefore examined reproductive output of Siphonaria denticulata on rocky shores and seawalls in Sydney Harbour. Sampling provided quantitative data on densities and sizes of limpets and number and lengths of egg-ribbons to test the hypothesis that reproductive output would be smaller on seawalls. From the results, experiments were designed to test the hypotheses that: (1) size of egg-ribbons in each habitat is related to different rates of survival (i.e. large egg-ribbons were not observed on seawalls because they persist there for less time than on rocky shores), (2) size of egg-ribbons depends on size of adults (i.e. long egg-ribbons are not observed on seawalls because large adult limpets are sparse or absent) and (3) intrinsic characteristics of seawalls alter the way eggs are laid (i.e. adults are not able to lay longer eggribbons on seawalls).

\section{MATERIALS AND METHODS}

Density and sizes of Siphonaria denticulata and egg-ribbons. Eight different shores were sampled in Sydney Harbour, 4 of them having vertical sandstone seawalls and 4 having natural horizontal rocky shores (Fig. 1). Hereafter, seawalls and rocky shores are referred to as habitats and shores to as locations. Locations were selected because they had either a seawall or a rocky shore extensive enough for the proposed sampling (at least $40 \mathrm{~m}$ long). They had large populations of $S$. denticulata ( $>100$ ind. $\mathrm{m}^{-2}$ ). Locations were separated by at least $100 \mathrm{~m}$. Sampling was restricted to the upper midshore (0.9 to $1.1 \mathrm{~m}$ above Indian Low Water Springs), where egg-ribbons were more abundant and $S$. denticulata larger. The sampling design did not eliminate potential sources of confounding, for example due to differences in exposure and slope, but was a sensible scheme on the fragmented shoreline of Sydney Harbour (Chapman \& Bulleri 2003). All locations were, however, located inside Sydney Harbour and apparently experienced similar wave-wash due to intense maritime traffic. It is therefore unlikely that differences in exposure exist between the 2 studied habitats across all locations. In addition, because sea- 


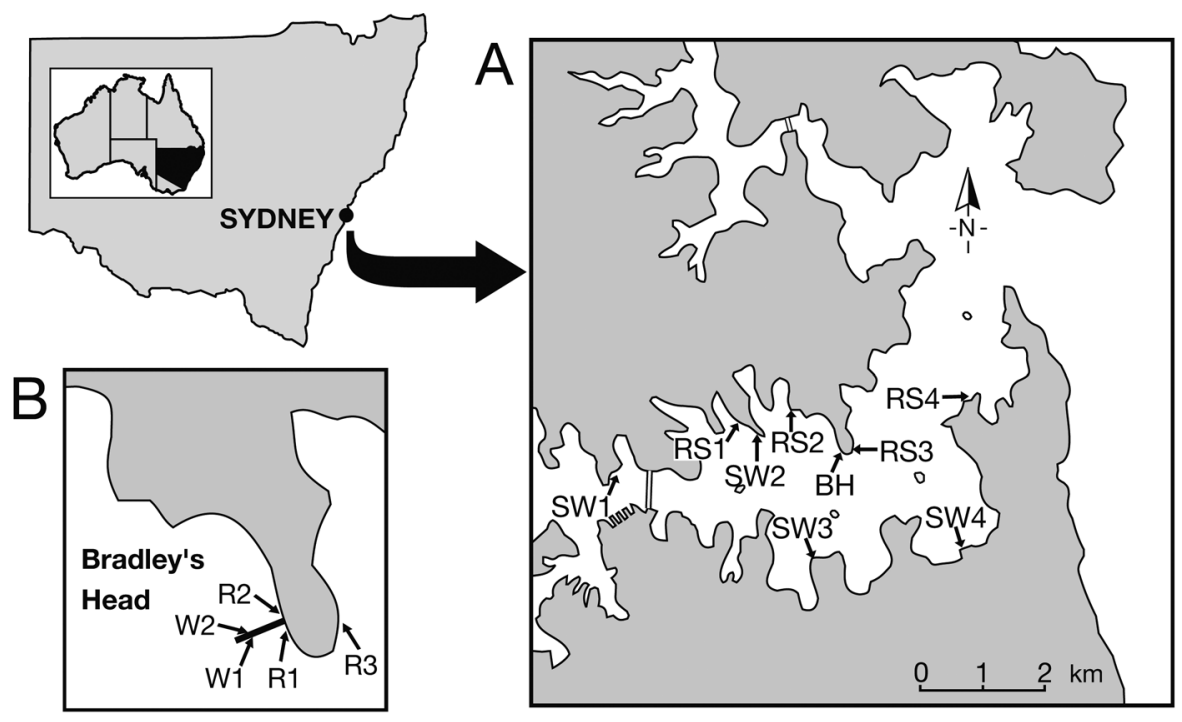

Fig. 1. Study locations in Sydney Harbour, New South Wales, Australia. (A) Locations sampled between February and March 2005 (RS1 to 4: natural horizontal rocky shores; SW1 to 4: seawalls; BH: Bradley's Head, location where sites were selected for experiments). (B) Spatial configuration of sites for experiments (Expt 1-W1 and W2: seawall sites; R1 and R2: rocky shore sites; Expt 2-W1: seawall [site for transplanted treatment]; R1: rocky shore [site for translocated treatment]; R3: rocky shore [site for control treatment])

walls are built vertically and are not even gently sloped, comparisons among seawalls of different slope were not possible. Patches of vertical rocky shores are present in Sydney Harbour, but these were not extensive enough for the proposed sampling design and were not incorporated in it. The objective of this paper was therefore a comparison of sizes and reproductive output of $S$. denticulata between natural horizontal rocky shores and the most common artificial habitat in which this limpet is found.

Each location was sampled between February and March 2005, during the peak in the spawning season (Creese 1980). Although previous work suggested a relation between copulation/spawning and periods of full/new moon (Creese 1980, Iwasaki 1995), there was evidence that spawning may not be synchronised among different populations and larger animals may lay >1 egg-ribbon per 2 wk period (Creese 1980). Consequently, sampling was done every week for 6 consecutive weeks to determine reproductive output.

Two different sites, 5 to $8 \mathrm{~m}$ long and separated by at least $10 \mathrm{~m}$, were sampled per location at each time of sampling. Egg-ribbons and all Siphonaria denticulata were counted and measured in 5 random quadrats (25 cm alongshore and $20 \mathrm{~cm}$ upshore) at each site (Chapman \& Bulleri 2003). Quadrats within the same site were separated by at least $50 \mathrm{~cm}$. Three size classes were sampled: juveniles $(<10 \mathrm{~mm})$, small adults (10 to $15 \mathrm{~mm}$ ) and large adults (>15 mm; Creese 1980).

Manipulative experiments. Two different experiments were designed to test hypotheses about the observed patterns of length-frequency distributions of egg-ribbons on seawalls and rocky shores (Table 1). 'Long' ribbons, defined as those longer than $30 \mathrm{~mm}$, were not found on seawalls and 'small' ribbons ( $<15 \mathrm{~mm}$ ) were found on seawalls and on rocky shores.

The first experiment tested the model that long eggribbons are absent from seawalls, because they do not survive or fragment on seawalls. To test this model, it was necessary to obtain egg-ribbons of both kinds and to allocate them to sites on seawalls and rocky shores, in order to compare how long they lasted in each habitat. To achieve this, adult animals (10 to $30 \mathrm{~mm}$ ) were collected from the field a day after a full moon and caged on sandstone plates $(15 \times 15 \times 1 \mathrm{~cm})$, on which they laid egg-ribbons. In order to maximise the number of egg-ribbons obtained, this procedure was done on the shore and in an aquarium at the same time. After $4 \mathrm{~d}$, plates with egg-ribbons were collected and randomly allocated to 4 sites at Bradley's Head, 2 on each side of a seawall that runs perpendicular to the shoreline (Sites 1 and 2; Fig. 1) and 2 on the rocky shore at each side of the seawall (Sites 3 and 4). Sites were $<20 \mathrm{~m}$ from each other. There was a mean of 3.18 egg ribbons $( \pm 1.54)$ per plate. Plates were attached by stainless screws inserted into rawl-plugs in the substrata. Previous observations have shown that eggribbons persisted on natural rocky shores between 8 and $10 \mathrm{~d}$ (Creese 1980). Thus, the experiment was left in the field for $8 \mathrm{~d}$, between 1 and 9 March 2005. Plates were photographed every $2 \mathrm{~d}$, and egg-ribbons were measured in the laboratory by means of image 
Table 1. Summary of logical structure of experimental design (see 'Materials and methods' for details. ER: egg-ribbons; RS: rocky shore; SW: seawall; LiSW: limpets from seawall; TpSW: limpets transplanted to seawall; LiRS: control limpets on rocky shore

\begin{tabular}{|lll}
\hline Observation & \multicolumn{1}{c}{ Explanatory models } & \multicolumn{1}{c}{ Hypotheses } \\
\hline $\begin{array}{l}\text { Egg-ribbons on seawalls are } \\
\text { smaller than on rocky shores }\end{array}$ & $\begin{array}{l}\text { 1. Egg-ribbons of the same range of sizes are laid } \\
\text { on each habitat, but there are differences in } \\
\text { survival according to their size }\end{array}$ & $\begin{array}{l}\text { Survival of long ER (>30 mm): ER } \\
\text { SW }<\text { ER RS } \\
\text { Survival of short ER ( }<15 \mathrm{~mm} \text { ): ER } \\
\text { SW }=\text { ER RS }\end{array}$ \\
& $\begin{array}{l}\text { 2. Egg-ribbons have different ranges of sizes } \\
\text { between habitats when they are laid because: }\end{array}$ & \\
& $\begin{array}{l}\text { 2.1. there are differences in size of limpets } \\
\text { between habitats }\end{array}$ & ER length: LiSW $<$ TpSW $=$ LiRS \\
& or 2.2 there are differences between habitats that \\
& affect spawning behaviour of limpets & ER length: LiSW $=$ TpSW $<$ LiRS
\end{tabular}

analysing software. There were no significant differences in longevity between egg masses of different origins at each site $\left(\chi^{2}\right.$ contingency tests, $\left.\mathrm{p}>0.05\right)$.

Because large limpets are scarcely found on seawalls and egg-ribbons there are always small $(<20 \mathrm{~mm})$, the second experiment tested the alternative models that lengths of egg-ribbons in each habitat are determined by: (1) the size of adult limpets on seawalls or rocky shores or (2) the intrinsic characteristics of habitat affecting spawning behaviour of the limpets in each habitat. The first model predicts that large adults transplanted from a rocky shore to a seawall will lay longer egg-ribbons on the seawall than do animals naturally found on seawalls. In addition, these ribbons will have a similar length-frequency distribution to those of limpets found on rocky shores. The second model predicts that transplanted large adults will lay shorter egg-ribbons than control limpets on rocky shores and of similar length to egg-ribbons laid by residents of seawalls.

This second experiment included 3 treatments. Large adults (15 to $25 \mathrm{~mm}$ long) originating from the upper midshore level of the rocky shore at Bradley's Head were transplanted to the same tidal level on a seawall 100s of metres away. Limpets were similarly translocated to a rocky shore close to that seawall to test for effects of relocating animals to an unfamiliar site with different conditions (Chapman 1986). A third treatment included animals caged on the same rocky shore of origin, to compare length-frequency distributions of egg-ribbons with those of the other 2 treatments. A true 'undisturbed' treatment was not possible because animals needed to be picked up prior to being caged, in order to secure the same number of limpets in each replicate. Animals were randomly collected from a midshore area, distributed among the different treatments and confined to cages made of $5 \mathrm{~mm}$ plastic mesh with basal dimensions of $11 \times 11 \mathrm{~cm}$ and $2 \mathrm{~cm}$ height. Ten cages, with 8 limpets in each, were allo- cated to each habitat. The experiment began as soon as limpets were caged at the 3 sites. Ideally, however, limpets transplanted to the seawall should have been kept in cages for at least several weeks prior to the beginning of the experiment. This would, for example, help to avoid potential confounding caused by a different previous history between limpets transplanted from rocky shores and those living on seawalls. This could not be achieved, because preliminary experiments showed that large limpets transplanted to seawalls suffer great mortality 3 to 4 wk after being transplanted (authors' unpubl. data). This limitation of the experiment has therefore been taken into account when interpreting the results of this work.

\section{RESULTS}

\section{Density and sizes of Siphonaria denticulata and egg-ribbons}

Seawalls and rocky shores at Sydney Harbour had similar numbers of Siphonaria denticulata at each sampling time (Table 2). The proportions of different size classes differed between the 2 habitats $\left(\chi^{2}=1088, \mathrm{df}=\right.$ $2, \mathrm{p}<0.005)$. Populations on seawalls were mainly composed of juveniles $(78 \%)$ and small adults $(22 \%$; Fig. 2). On rocky shores, large adults were found in a greater proportion $(24 \%)$ than on seawalls $(<1 \%)$.

Egg-ribbons were always more numerous on rocky shores than on seawalls $\left(\chi^{2}=390\right.$, df $\left.=1, \mathrm{p}<0.005\right)$ and showed significant differences in mean number for 4 out of 6 sampling times (Table 3). Mean length of eggribbons was greater on rocky shores than on seawalls (Table 4), and the length-frequency distributions of ribbons were significantly different (KolmogorovSmirnov [KS] test, $D_{\max }=0.50, \mathrm{p}<0.01$; Fig. 3). The main difference between the 2 habitats was in the absence of egg-ribbons longer than $20 \mathrm{~mm}$ on sea- 
walls. There was, on average, $47.1 \mathrm{~mm}$ of egg-ribbon per quadrat on rocky shores as opposed to $2.7 \mathrm{~mm}$ on seawalls. In addition, the number of eggs per millimetre of egg-ribbon was not significantly different between habitats for egg ribbons smaller than $20 \mathrm{~mm}$ $\left(F_{1,42}=0.02, \mathrm{p}>0.05\right)$, nor between egg-ribbons of the same length from the 2 habitats (5 to 10, 10 to 15 and 15 to $20 \mathrm{~mm}_{;} F_{2,42}=0.12, \mathrm{p}>0.05$ ). The mean diameter of eggs was $103.7 \mu \mathrm{m}$ on seawalls $(\mathrm{n}=200$ eggs; 20 eggribbons) and $105.4 \mu \mathrm{m}$ on rocky shores $(\mathrm{n}=250$ eggs; 25 egg-ribbons). There were no significant differences in egg diameter between egg-ribbons from each of the 2 habitats $\left(F_{1,24}=2.58, \mathrm{p}>0.05\right)$.

\section{Survival of egg-ribbons}

In the first experiment, more egg-ribbons remained on the plates on the seawall than on the rocky shore after $8 \mathrm{~d}$ (Table 5). In general, long and short eggribbons disappeared significantly faster from rocky shores. Long egg-ribbons lasted more time than did smaller ones at Site 1 on the seawall; at the other 3 sites, there were no significant differences.

\section{Size of adults and egg-ribbons}

Daily observations showed that caged animals laid egg-ribbons at the 3 sites and in most of the cages. Unfortunately, many of the cages from the translocated treatment were found ripped off (most probably by vandals) after 8 d. Egg-ribbons presumably laid by caged animals were, however, found undamaged inside the spaces occupied by the cages; these were therefore measured. There were no significant differences in length-frequency distributions among eggribbons laid by limpets in the 3 different treatments (KS tests, $\mathrm{p}>0.05$ ). The experiment was run for 4 additional days, and egg-ribbons were measured in the other 2 intact treatments. Animals transplanted to the seawall laid longer egg-ribbons than those found on

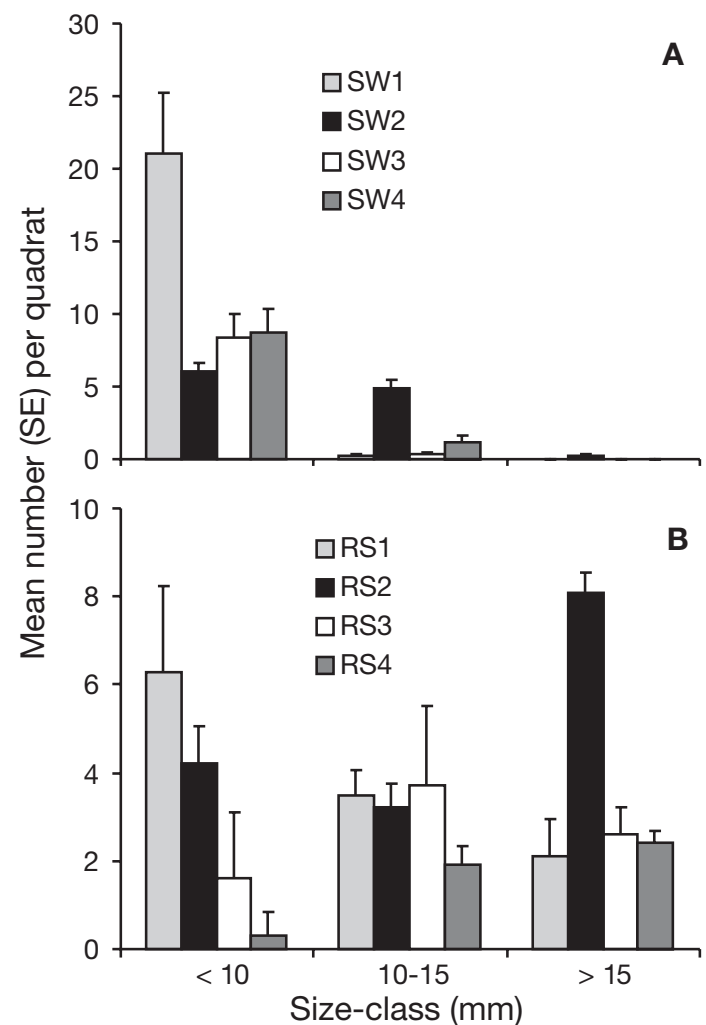

Fig. 2. Siphonaria denticulata. Mean number $( \pm \mathrm{SE} ; \mathrm{n}=10$ quadrats) of each size class on: (A) seawalls and (B) natural horizontal rocky shores in Sydney Harbour. Values are from Time 1 and are representative of the pattern found in each habitat throughout the study. Location codes as in Fig. 1

seawalls during the sampling survey ( 15 to $45 \mathrm{~mm}$ vs. 5 to $20 \mathrm{~mm}$ ). Again, there were no significant differences in length-frequency distributions between egg-ribbons laid by limpets caged on the rocky shore and those laid by animals transplanted to the seawall $\left(D_{\max }\right.$ $=0.13, \mathrm{p}>0.05$; Fig. 4). Animals transplanted to the seawall laid a smaller number of egg-ribbons that those caged on their rocky shore (15 and 30, respectively), but analyses based on numbers of egg-ribbons in each cage as replicate values did not show significant differences among the 2 treatments $\left(F_{1,19}=2.95\right.$,

Table 2. Siphonaria denticulata. Analyses of densities of individuals on seawalls and rocky shores (referred to as 'habitat') at Sydney Harbour. ns: not significant, $\mathrm{p}>0.05 ;{ }^{*} \mathrm{p}<0.05 ;{ }^{* *} \mathrm{p}<0.01$; Time 1: 20 Feb 2005; Time 2: 27 Feb 2005; Time 3: 6 Mar 2005; Time 4: 13 Mar 2005; Time 5: 21 Mar 2005; Time 6: 29 Mar 2005

\begin{tabular}{|c|c|c|c|c|c|c|c|c|c|c|c|c|c|}
\hline & \multirow[t]{2}{*}{ df } & \multicolumn{2}{|c|}{ Time 1} & \multicolumn{2}{|c|}{ Time 2} & \multicolumn{2}{|c|}{ Time 3} & \multicolumn{2}{|c|}{ Time 4} & \multicolumn{2}{|c|}{ Time 5} & \multicolumn{2}{|c|}{ Time 6} \\
\hline & & MS & $F$ & MS & $F$ & MS & $F$ & MS & $F$ & MS & $F$ & MS & $F$ \\
\hline Habitat $=\mathrm{Ha}$ & 1 & 2.95 & $0.63 \mathrm{~ns}$ & 221.11 & $0.72 \mathrm{~ns}$ & 594.05 & $1.47 \mathrm{~ns}$ & 456.01 & $2.33 \mathrm{~ns}$ & 5.40 & $5.04 \mathrm{~ns}$ & 18.02 & $4.29 \mathrm{~ns}$ \\
\hline Location = Lo(Ha) & 6 & 4.71 & $1.95 \mathrm{~ns}$ & 307.35 & $2.79 \mathrm{~ns}$ & 405.46 & $2.01 \mathrm{~ns}$ & 195.41 & $2.71 \mathrm{~ns}$ & 1.07 & $1.90 \mathrm{~ns}$ & 4.20 & $4.05^{*}$ \\
\hline Site $=\mathrm{Si}(\mathrm{Ha} \times \mathrm{Lo})$ & 8 & 2.41 & $3.13^{* *}$ & 110.11 & $3.37^{* *}$ & 201.92 & $2.48^{*}$ & 72.21 & $3.00^{* *}$ & 0.56 & $2.20^{*}$ & 1.04 & $1.55 \mathrm{~ns}$ \\
\hline Residual & 64 & 0.77 & & 32.66 & & 81.44 & & 24.07 & & 0.26 & & 0.67 & \\
\hline Cochran's test $(C)$ & & $0.15 \mathrm{~ns}$ & & $0.16 \mathrm{~ns}$ & & $0.21 \mathrm{~ns}$ & & $0.16 \mathrm{~ns}$ & & $0.14 \mathrm{~ns}$ & & $0.23 \mathrm{~ns}$ & \\
\hline
\end{tabular}


Table 3. Siphonaria denticulata. Analyses of numbers of egg-ribbons on seawalls and rocky shores (referred to as 'habitat') at Sydney Harbour. ns: not significant, $\mathrm{p}>0.05 ;{ }^{*} \mathrm{p}<0.05 ;{ }^{* *} \mathrm{p}<0.01$; Time 1: 20 Feb 2005; Time 2: 27 Feb 2005 ; Time 3: 6 Mar 2005; Time 4: 13 Mar 2005; Time 5: 21 Mar 2005; Time 6: 29 Mar 2005

\begin{tabular}{|c|c|c|c|c|c|c|c|c|c|c|c|c|c|}
\hline & \multirow[t]{2}{*}{$\mathrm{df}$} & \multicolumn{2}{|r|}{ Time 1} & \multicolumn{2}{|c|}{ Time 2} & \multicolumn{2}{|c|}{ Time 3} & \multicolumn{2}{|c|}{ Time 4} & \multicolumn{2}{|c|}{ Time 5} & \multicolumn{2}{|c|}{ Time 6} \\
\hline & & MS & $F$ & MS & $F$ & MS & $F$ & MS & $F$ & MS & $F$ & MS & $F$ \\
\hline Habitat $=\mathrm{Ha}$ & 1 & 9.49 & $14.97^{* *}$ & 180.00 & $32.38^{* *}$ & 3.20 & $0.58 \mathrm{~ns}$ & 18.01 & $11.46^{*}$ & 19.01 & $3.47 \mathrm{~ns}$ & 227.81 & $49.39^{* *}$ \\
\hline Location = Lo(Ha) & 6 & 0.63 & $0.62 \mathrm{~ns}$ & 5.56 & $3.32 \mathrm{~ns}$ & 5.56 & $1.90 \mathrm{~ns}$ & 1.57 & $3.56 \mathrm{~ns}$ & 5.48 & $0.88 \mathrm{~ns}$ & 4.61 & $1.05 \mathrm{~ns}$ \\
\hline Site $=\mathrm{Si}(\mathrm{Ha} \times$ Lo $)$ & 8 & 1.01 & $5.22^{* *}$ & 1.67 & $0.37 \mathrm{~ns}$ & 2.92 & $1.42 \mathrm{~ns}$ & 0.44 & $2.18^{*}$ & 6.24 & $5.45^{* *}$ & 4.41 & $1.27 \mathrm{~ns}$ \\
\hline Residual & 64 & 0.19 & & 289.20 & & 2.06 & & 0.20 & & 1.14 & & 3.49 & \\
\hline Cochran's test $(C)$ & & $0.17 \mathrm{~ns}$ & & $0.20 \mathrm{~ns}$ & & $0.46^{* *}$ & & $0.21 \mathrm{~ns}$ & & $0.29^{* *}$ & & $0.39^{* *}$ & \\
\hline
\end{tabular}

Table 4. Siphonaria denticulata. Summary of reproductive output on seawalls and rocky shores at Sydney Harbour. Location codes as in Fig. 1

\begin{tabular}{|c|c|c|c|c|c|}
\hline Habitat & Location & $\begin{array}{c}\text { Mean number of } \\
\text { egg-ribbons (quadrat }^{-1}, \pm \mathrm{SE} \text { ) }\end{array}$ & $\begin{array}{c}\text { Mean length of } \\
\text { egg-ribbons (mm, } \pm \mathrm{SD})\end{array}$ & $\begin{array}{c}\text { Egg-ribbon } \\
\left(\mathrm{mm}_{\text {quadrat }}{ }^{-1}\right)\end{array}$ & $\begin{array}{l}\text { Egg-ribbon length } \\
\text { range (mm) }\end{array}$ \\
\hline Seawall & $\begin{array}{l}\text { SW1 } \\
\text { SW2 } \\
\text { SW3 } \\
\text { SW4 }\end{array}$ & $\begin{array}{l}0.42 \pm 0.13 \\
0.67 \pm 0.22 \\
0.13 \pm 0.09 \\
0.02 \pm 0.02\end{array}$ & $\begin{aligned} & 7.28 \pm 1.57 \\
& 9.50 \pm 3.47 \\
& 10.63 \pm 4.14 \\
& 10.00\end{aligned}$ & $\begin{array}{l}3.03 \\
6.33 \\
1.42 \\
0.17\end{array}$ & $\begin{array}{c}5-10 \\
5-15 \\
5-20 \\
10\end{array}$ \\
\hline Rocky shore & $\begin{array}{l}\text { RS1 } \\
\text { RS2 } \\
\text { RS3 } \\
\text { RS4 }\end{array}$ & $\begin{array}{l}2.07 \pm 0.27 \\
2.92 \pm 0.44 \\
2.97 \pm 0.36 \\
1.68 \pm 0.23\end{array}$ & $\begin{array}{l}17.44 \pm 11.76 \\
19.47 \pm 16.65 \\
21.92 \pm 12.73 \\
18.22 \pm 9.25\end{array}$ & $\begin{array}{l}36.05 \\
56.78 \\
65.03 \\
30.67\end{array}$ & $\begin{array}{l}5-70 \\
5-110 \\
5-75 \\
5-55\end{array}$ \\
\hline
\end{tabular}

$\mathrm{p}>0.05)$. Additionally, the number of eggs per millimetre was estimated from 6 ribbons with lengths of 20 to $40 \mathrm{~mm}$ in each of the 3 treatments and from a random sample (of 6 ribbons) obtained from the original rocky shore. There were no significant differences among the different samples $\left(F_{3,20}=0.92, \mathrm{p}>0.05\right)$.

\section{DISCUSSION}

The reproductive output of Siphonaria denticulata was significantly smaller on seawalls than on rocky shores at Sydney Harbour, in terms of numbers and sizes of egg masses, although each habitat can support similar densities of limpets. The experimental results suggested that these differences are related to the sizes of adults found in each habitat. Thus, egg-ribbons longer than $20 \mathrm{~mm}$ were not found on the 4 seawalls surveyed, but were frequent on rocky shores where large adults are common. Numbers of ribbons were always greater on rocky shores than on seawalls, but the difference between the 2 habitats was not significant for 2 out of the 6 sampling times, when densities of egg-ribbons were small. These dates were $3 \mathrm{~d}$ before and $11 \mathrm{~d}$ after a full moon, respectively. Previous observations have shown that spawning occurs around a full/new moon (Creese 1980) and that egg-ribbons
Table 5. Siphonaria denticulata. Percentage of egg-ribbons remaining on the plates from the first experiment after $8 \mathrm{~d}$. Comparison between habitats and sizes were done through Fisher's exact test of independence. ns: not significant, p > $0.05 ;{ }^{*} \mathrm{p}<0.05 ;{ }^{* *} \mathrm{p}<0.01$; SW: seawall; RS: rocky shore

\begin{tabular}{|lccc|}
\hline \multicolumn{2}{|c|}{$\begin{array}{c}\text { Long ribbons } \\
(>30 \mathrm{~mm})(\%)\end{array}$} & $\begin{array}{c}\text { Small ribbons } \\
(<15 \mathrm{~mm})(\%)\end{array}$ & $\begin{array}{c}\text { Long vs. small } \\
\text { (within site) }\end{array}$ \\
\hline SW Site 1 & 90.0 & 38.7 & $\mathrm{~L}>\mathrm{S}^{*}$ \\
SW Site 2 & 77.8 & 62.5 & $\mathrm{~ns}$ \\
RS Site 3 & 20.0 & 0 & $\mathrm{~ns}$ \\
RS Site 4 & 42.9 & 35.0 & $\mathrm{~ns}$ \\
SW vs. RS & & $\mathrm{SW}>\mathrm{RS}^{* *}$ & $\mathrm{SW}>\mathrm{RS}^{*}$ \\
(between habitats) & & \\
\hline
\end{tabular}

stay on the shore for about $10 \mathrm{~d}$. This could explain the small number of egg-ribbons in each habitat on those dates.

The first experiment showed that the persistence of egg ribbons was more affected by the local conditions at any given site (i.e. exposure to wave action, desiccation) than by the type of habitat. Ocaña \& Emson (1999) found that the number of egg-ribbons of Siphonaria pectinata was smaller on exposed rocky sites than on sheltered ones. In our experiment, 'long' and 'short' egg-ribbons lasted comparatively less time on 1 rocky shore, with only long ones remaining until the end of 


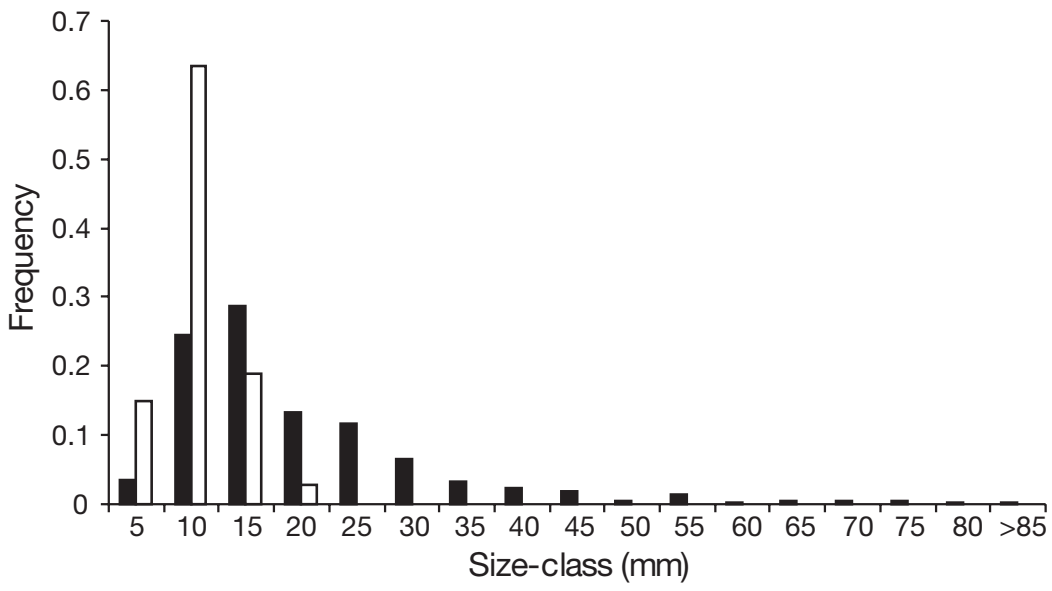

Fig. 3. Siphonaria denticulata. Length-frequency distributions of egg-ribbons on rocky shores (black bars; $\mathrm{n}=578$ ) and seawalls (white bars; $\mathrm{n}=74$ ) in Sydney Harbour

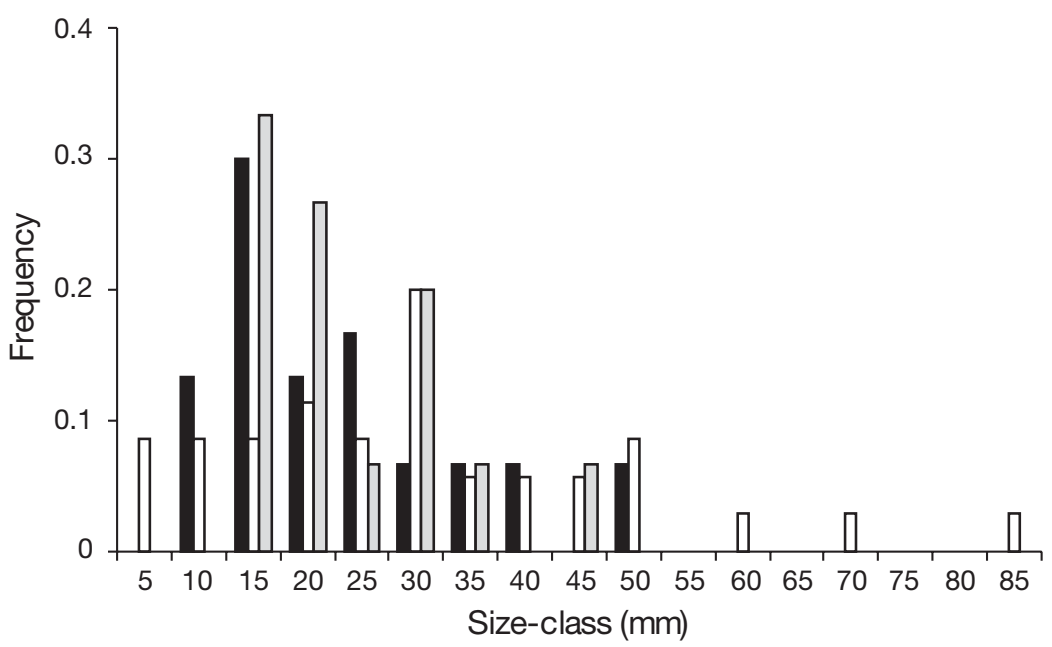

Fig. 4. Siphonaria denticulata. Length-frequency distributions of egg-ribbons in the second experiment (black bars: original rocky shore $[\mathrm{n}=30]$; white bars: translocated to a new rocky shore [ $\mathrm{n}=35]$; grey bars: transplanted to a seawall $[\mathrm{n}=15])$. Data from original rocky shore and animals transplanted to the seawall were obtained after $12 \mathrm{~d}$; data from limpets translocated to a different rocky shore were obtained after $8 \mathrm{~d}$

the experiment. At one of the seawall sites, long eggribbons persisted for a longer time than did smaller ones, whilst at the other site there was no significant difference. These experimental results do not support the model proposed, i.e. that long egg-ribbons are not observed on seawalls because they disappear faster than do short ones.

The second experiment provides support for the model in that differences in reproductive output are related to the maximal adult size observed in each habitat. Thus, when large adults were transplanted to the seawall, they laid longer egg-ribbons than did smaller limpets naturally living on the seawall during the sampling period. In addition, the length-frequency distribution of eggribbons was not significantly different from that of adult limpets in their habitat of origin. Because limpets transplanted to the seawall were not previously acclimated to this habitat due to experimental limitations (see 'Materials and methods') and large limpets are scarce on seawalls, it was not possible to determine whether large limpets hypothetically living on seawalls would have a similar reproductive output to animals of the same size living on natural rocky shores. Nevertheless, the combined results from sampling and experimental manipulations suggested a strong correlation between adult size and reproductive output of Siphonaria denticulata in terms of number and length of egg-ribbons.

In fact, reproductive output of Siphonaria denticulata and other siphonarians has been shown to increase with size and age (Creese 1980, Quinn 1988b, Godoy \& Moreno 1989), as happens in other gastropods (Chaparro et al. 1999, Muthiah \& Sampath 2000, Valentinsson 2002). For S. denticulata, Creese (1980) showed that large adults on rocky shores laid longer egg-ribbons and had greater fecundity than did smaller animals. Consequently, the observed differences in adult size between habitats may account for the results obtained here. Creese (1980) found, however, some differences in number and mean length of egg-ribbons among populations of $S$. denticulata from different rocky shores. Quinn $(1988 \mathrm{a}, \mathrm{b})$ showed that populations of $S$. diemenensis on the same shore and under different environmental conditions (i.e. microhabitat features, availability of food) showed differences in maximal sizes attained, growth rates and reproductive outputs. In our study, reproductive output was always greater on rocky shores than on seawalls. Therefore, one or more factors may be acting differently on populations of $S$. denticulata in each habitat, resulting in different adult sizes and, consequently, in different reproductive output (Fig. 5). For example, potential differences in dynamics and availability of algae between the 2 habitats could have a strong effect on growth rate and survival and 


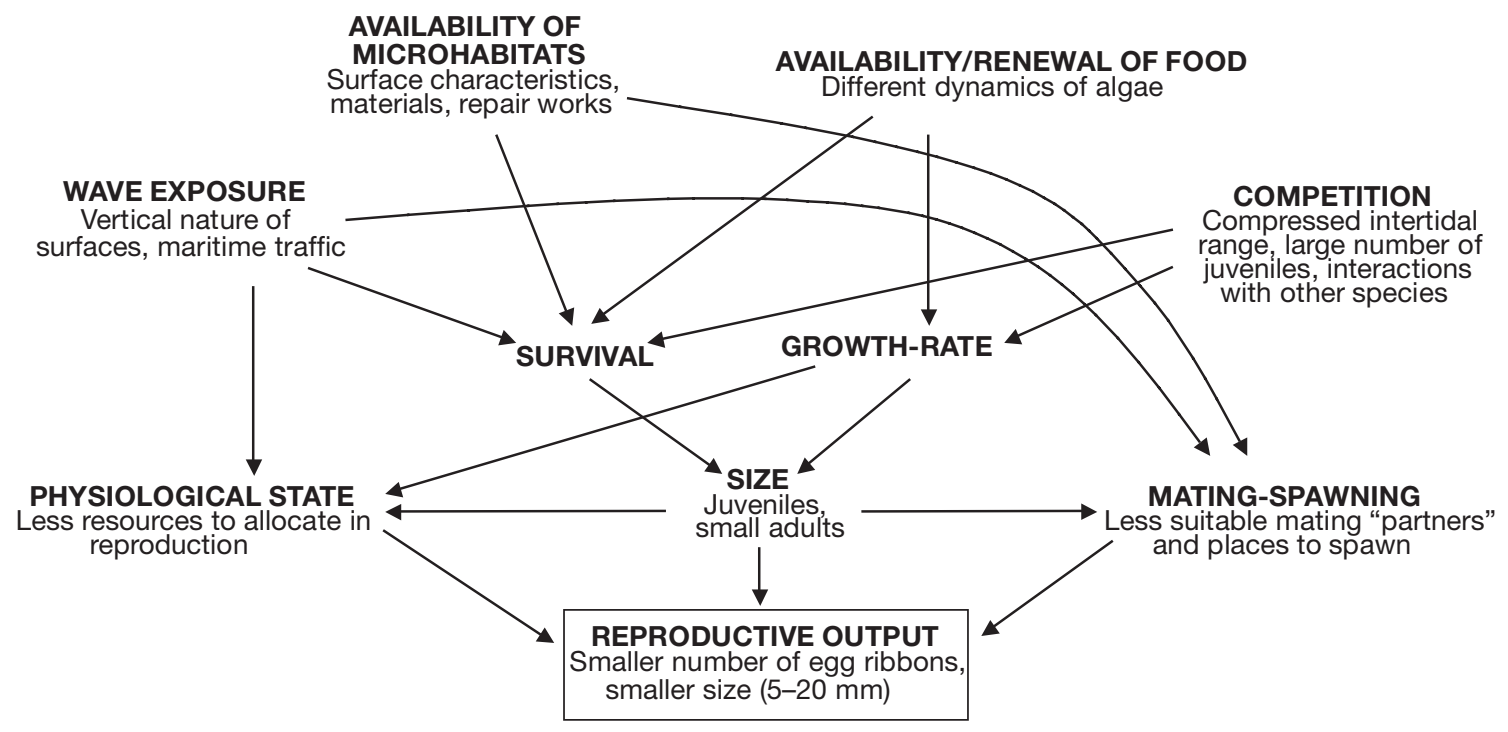

Fig. 5. Siphonaria denticulata. Summary of factors that may affect reproductive output of populations on seawalls

could reduce the resources to be allocated to reproductive effort for populations on seawalls (Quinn 1988b, Pal \& Hodgson 2004). Additionally, a shortage of food on seawalls may affect intensity and relative importance of competitive interactions among different grazers. Intra- and interspecific competition for food has been shown to affect body weight, survival and growth rate in siphonarians (Creese \& Underwood 1982, Ortega 1985, Lasiak \& White 1993).

Differences in population structure of Siphonaria denticulata between natural rocky shores and seawalls translate, therefore, into quantitative differences in terms of reproductive output. These differences highlight important implications in the self-maintenance of intertidal organisms inhabiting seawalls. Persistence of local populations of organisms with larval dispersal depends on recolonisation from the plankton (Underwood \& Fairweather 1989). Thus, because of the smaller reproductive output of $S$. denticulata on seawalls, replenishment of their populations in this habitat with new recruits may depend on the existence of populations elsewhere, i.e. on natural rocky shores. An ongoing reduction of rocky shores in urban areas could, therefore, have negative effects on the survival of local populations unless larvae are supplied from other geographic areas. Long-distance dispersal of long-lived planktonic larvae is common in the sea (Thorson 1950, Scheltema 1988). Creese (1980) suggested that, according to spawning and recruitment periods, larvae of $S$. denticulata could have a maximal planktonic life of around 10 wk (Creese 1980), which could be enough to allow larval interchange among populations. On the other hand, topography and oceanographic features such as coastal currents and eddies alter larval dispersal (Eckman 1996, Cowen et al. 2000). In the case of bays and estuaries, differences in physical properties among water masses may limit water interchange with the open sea and enhance larval retention close to source populations (Kingsford \& Suthers 1994). This will influence the extent to which local recruitment will depend on local larval production (Kinlan et al. 2005) and the survival of such populations.

Other factors that are not dependent on the size of egg masses and the number of produced larvae, such as survival during planktonic life and settlement, may also influence maintenance of populations of intertidal organisms (Eckman 1996). Hypothetically, populations on seawalls producing less larvae per capita than those on natural habitats may still produce numbers sufficient to assure a supply of new recruits to replenish existing populations. Alternatively, larvae from eggs on seawalls may, for whatever reason, be in better physiological condition and, thus, perform better than larvae from populations on rocky shores. These issues were, however, not within the scope of this paper and were not investigated here. Nevertheless, our results strongly suggest a potential problem in the sustainability of populations living on seawalls, which highlights the importance of further research for understanding the ecological processes on seawalls, in particular, and in artificial habitats, in general.

\section{CONCLUSION}

Although previous studies have shown that seawalls can provide habitat for populations of some intertidal organisms that are naturally found on rocky reefs (Chapman 2003, Chapman \& Bulleri 2003), our results 
suggest that merely recording the presence of organisms or their densities is not enough to assess the value of artificial intertidal structures as surrogate habitats. It is therefore necessary to investigate whether populations of organisms on these artificial habitats can maintain themselves. As proliferation of artificial structures will undoubtedly increase in urban coastal areas, this information will enhance our ability to design artificial structures in order to ameliorate the impact of their construction on natural assemblages and to maintain similar levels of biodiversity as found in natural habitats (Connell 2000, Chapman 2003).

Acknowledgements. This research was funded by the Australian Research Council through the Centre for Research on Ecological Impacts of Coastal Cities. J.M. held a fellowship funded by Conselleria de Innovación, Industria e Comercio (Xunta de Galicia, Spain). We are very grateful to A. Boden, M. Boutry, S. Brillant, T. Espinoza, S. Gartenstein, A. Grigaliunas, P. Hill, A. Jackson, C. Myers, R. Reinfrank, J. Smith and T. Van Becelaere for assistance in the field work and all the entry and checking of data. Two anonymous reviewers provided improvements to the manuscript.

\section{LITERATURE CITED}

Bulleri F (2005) Role of recruitment in causing differences between intertidal assemblages on seawalls and rocky shores. Mar Ecol Prog Ser 287:53-65

Bulleri F, Chapman MG (2004) Intertidal assemblages on artificial and natural habitats in marinas on the north-west coast of Italy. Mar Biol 145:381-391

Bulleri F, Menconi M, Cinelli F, Benedetti-Cecchi L (2000) Grazing by two species of limpets on artificial reefs in the northwest Mediterranean. J Exp Mar Biol Ecol 255:1-19

Chaparro OR, Oyarzun RF, Vergara AM, Thompson RJ (1999) Energy investment in nurse and egg capsules in Crepidula fornicata Lamarck (Gastropoda, Calyptraeidae) and its influence on the hatching size of the juvenile. J Exp Mar Biol Ecol 232:261-274

Chapman MG (1986) Assessment of some controls in experimental transplants of intertidal gastropods. J Exp Mar Biol Ecol 103:181-201

Chapman MG (2003) Paucity of mobile species on constructed seawalls: effects of urbanization on biodiversity. Mar Ecol Prog Ser 264:21-29

Chapman MG, Bulleri F (2003) Intertidal seawalls-new features of landscape in intertidal environments. Landsc Urban Plann 62:159-172

Collinge SK (1996) Ecological consequences of habitat fragmentation: implications for landscape architecture and planning. Landsc Urban Plann 36:59-77

Connell SD (2000) Floating pontoons create novel habitats for subtidal epibiota. J Exp Mar Biol Ecol 247:183-194

Cowen RK, Lwiza KMM, Sponaugle S, Paris CB, Olson DB (2000) Connectivity of marine populations: Open or closed? Science 287:857-859

Creese RG (1980) Reproductive cycles and fecundities of two species of Siphonaria (Mollusca: Pulmonata) in south-eastern Australia. Aust J Mar Freshw Res 31:37-47

Creese RG (1981) Patterns of growth, longevity and recruitment of intertidal limpets in New South Wales. J Exp Mar Biol Ecol 51:145-171
Creese RG, Underwood AJ (1982) Analysis of inter- and intraspecific competition amongst intertidal limpets with different methods of feeding. Oecologia 53:337-346

Davis JLD, Levin LA, Walther SM (2002) Artificial armored shorelines: sites for open-coast species in a southern California bay. Mar Biol 140:1249-1262

Dickman CR, Doncaster CP (1987) The ecology of small mammals in urban habitats. I. Populations in a patchy environment. J Anim Ecol 56:629-640

Dooley JL, Bowers MA (1998) Demographic responses to habitat fragmentation: experimental tests at the landscape and patch scale. Ecology 79:969-980

Eckman JE (1996) Closing the larval loop: linking larval ecology to the population dynamics of marine benthic invertebrates. J Exp Mar Biol Ecol 200:207-237

Fahrig L, Merriam G (1994) Conservation of fragmented populations. Conserv Biol 8:50-59

Glasby TM, Connell SD (1999) Urban structures as marine habitats. Ambio 28:595-598

Godoy C, Moreno CA (1989) Indirect effects of human exclusion from the rocky intertidal in southern Chile: a case of cross-linkage between herbivores. Oikos 54:101-106

Gray JS (1997) Marine biodiversity: patterns, threats and conservation needs. Biodivers Conserv 6:153-175

Hawkins SJ, Hartnoll RG (1983) Grazing of intertidal algae by marine invertebrates. Oceanogr Mar Biol Annu Rev 21: $195-282$

Iwasaki K (1995) Foraging and spawning rhythms of the pulmonate limpet Siphonaria sirius (Pilsbry): switching of activity period by a diurnal forager. J Molluscan Stud 61: 275-288

Kingsford MJ, Suthers IM (1994) Dynamic estuarine plumes and fronts: importance to small fish and plankton in coastal waters of NSW, Australia. Cont Shelf Res 14:655-672

Kinlan BP, Gaines SD, Lester SE (2005) Propagule dispersal and the scales of marine community process. Divers Distrib 11:139-148

Krauss J, Steffan-Dewenter I, Tscharntke T (2003) Local species inmigration, extinction, and turnover of butterflies in relation to habitat area and habitat isolation. Oecologia 137:91-602

Laakkonen J, Fisher RN, Case TJ (2001) Effect of land cover, habitat fragmentation and ant colonies on the distribution and abundance of shrews in southern California. J Anim Ecol 70:776-788

Lasiak TA, White DRA (1993) Microalgal food resources and competitive interactions among the intertidal limpets Cellana capensis (Gmelin, 1791) and Siphonaria concinna Sowerby, 1824. S Afr J Mar Sci 13:97-108

Lim HC, Sodhi NS (2004) Responses of avian guilds to urbanisation in a tropical city. Landsc Urban Plann 66:199-215

Madejczyk JC, Mundahl ND, Lehtinen RM (1998) Fish assemblages of natural and artificial habitats within the channel border of the upper Mississippi River. Am Midl Nat 139: 296-310

McDonnell MJ, Pickett STA (1990) Ecosystem structure and function along urban-rural gradients: an unexploited opportunity for ecology. Ecology 71:1232-1237

McDowall RM (1992) Particular problems for the conservation of diadromous fishes. Aquat Conserv 2:351-355

Moberg F, Rönnbäck P (2003) Ecosystem services of the tropical seascape: interactions, substitutions and restoration. Ocean Coast Manage 46:27-46

Muthiah P, Sampath K (2000) Spawn and fecundity of Cymatium (Monoplex) pileare and Cymatium (Linatella) cingulatum (Gastropoda: Ranellidae). J Molluscan Stud 66:293-300 
Ocaña TM, Emson RH (1999) Maturation, spawning and development in Siphonaria pectinata Linnaeus (Gastropoda: Pulmonata) at Gibraltar. J Molluscan Stud 65:185-193

Ortega S (1985) Competitive interactions among tropical intertidal limpets. J Exp Mar Biol Ecol 90:11-25

Pal P, Hodgson AH (2004) Reproductive seasonality and simultaneous hermaphroditism in two species of Siphonaria (Gastropoda: Pulmonata) from the southeast coast of South Africa. J Molluscan Stud 71:33-40

Petraitis PS (1987) Factors organizing rocky intertidal communities of New England: herbivory and predation in sheltered bays. J Exp Mar Biol Ecol 109:117-136

Pickett STA, Cadenasso ML, Grove JM, Nilon CH, Pouyat RV, Zipperer WC, Costanza R (2001) Urban ecological systems: linking terrestrial, ecological, physical, and socioeconomic components of metropolitan areas. Annu Rev Ecol Syst 32:127-157

Quinn GP (1988a) Ecology of the intertidal pulmonate limpet Siphonaria diemenensis Quoy and Gaimard. I. Population dynamics and availability of food. J Exp Mar Biol Ecol 117: 115-136

Quinn GP (1988b) Ecology of the intertidal pulmonate limpet Siphonaria diemenensis Quoy and Gaimard. II. Reproductive patterns and energetics. J Exp Mar Biol Ecol 117:137-156

Scheltema R (1988) Initial evidence for the transport of teleplanic larvae of benthic invertebrates across the east Pacific barrier. Biol Bull (Woods Hole) 174:145-152

Editorial responsibility: Roger N. Hughes (Contributing Editor), Bangor, UK
Smallwood KS (2001) Linking habitat restoration to meaningful units of animal demography. Restor Ecol 9:253-261

Thompson RC, Crowe TP, Hawkins SJ (2002) Rocky intertidal communities: past environmental changes, present status and predictions for the next 25 years. Environ Conserv 29: 168-191

Thorson G (1950) Reproductive and larval ecology of marine bottom invertebrates. Biol Rev 25:1-45

Underwood AJ (1978) An experimental evaluation of competition between three species of intertidal prosobranch gastropods. Oecologia 33:185-202

Underwood AJ, Fairweather PG (1989) Supply-side ecology and benthic marine assemblages. Trends Ecol Evol 4: $16-20$

Underwood AJ, Jernakoff P (1981) Effects of interactions between algae and grazing gastropods on the structure of a low-shore intertidal community. Oecologia 48: 221-233

Valentinsson D (2002) Reproductive cycle and maternal effects on offspring size and number in the neogastropod Buccinum undatum (L.). Mar Biol 140:1139-1147

Watkinson AR, Sutherland WJ (1995) Sources, sinks and pseudo-sinks. J Anim Ecol 64:126-130

Wolff WJ (1999) The conservation value of artificial habitats in the marine environment: a case study of the artificial rocky shores of The Netherlands. Aquat Conserv 9: $541-544$

Submitted: November 17, 2005; Accepted: February 13, 2006 Proofs received from author(s): September 5, 2006 